\title{
EDUCAÇÃO ALIMENTAR E NUTRICIONAL NO ENSINO MÉDIO TÉCNICO: UMA ABORDAGEM INTERDISCIPLINAR
}

\author{
Soraia Correa Mercante \\ Instituto Federal do Sertão Pernambucano (IF Sertão-PE), Pernambuco, Brasil \\ LUCIRLÂNdIA SheILA De MoraIS RuFino \\ Universidade de Pernambuco (UPE), Petrolina, Pernambuco, Brasil \\ JULIANA Vieira NunES \\ Universidade de Pernambuco (UPE), Petrolina, Pernambuco, Brasil \\ Poliana SimÕes LyRa \\ Universidade de Pernambuco (UPE), Petrolina, Pernambuco, Brasil \\ INGRID RAPHAELA SOUZA SILVA \\ Universidade de Pernambuco (UPE), Petrolina, Pernambuco, Brasil \\ Cristhiane Maria Bazílio de Omena Messias \\ Universidade de Pernambuco (UPE), Petrolina, Pernambuco, Brasil
}

\begin{abstract}
Resumo: A escola é um ambiente estratégico para promoção da saúde, exercendo grande influência na alimentação dos alunos. Nesse contexto, este relato de experiência objetiva contribuir com o desenvolvimento de ações que promovam a prática independente e autônoma de hábitos alimentares saudáveis que levem à promoção e à proteção da saúde. Trata-se de um relato de experiência associado a uma abordagem qualitativa realizado no segundo ano do ensino médio técnico em parceria com os docentes das disciplinas de educação física, sociologia e geografia. O projeto possibilitou a promoção de espaços de diálogos na comunidade escolar pelo fornecimento de material de apoio, através de jogos educativos que trouxeram uma abordagem da educação alimentar e nutricional de forma dinâmica e interativa.
\end{abstract}

Palavras-Chave: Educação. Saúde. Jogos educativos. Interdisciplinaridade.

\section{INTRODUÇÃO}

A escola é priorizada como ambiente estratégico para promoção da saúde, exercendo grande influência na alimentação dos alunos. A educação alimentar e nutricional se insere nesse contexto, já que a alimentação é um dos aspectos essenciais ao desenvolvimento de hábitos saudáveis (BARBOSA, 2009). Em legislação publicada em 16 de maio de 2018, o Presidente da República reafirma o reconhecimento da 
educação alimentar e nutricional (EAN) como estratégia de enfrentamento dos desafios na seara da alimentação, da nutrição e da saúde, a partir do momento em que altera o texto da Lei de Diretrizes e Bases da Educação (LDB) para incluir o tema transversal da EAN no currículo escolar (BRASIL, 2018).

A educação tem por finalidade o pleno desenvolvimento do educando, seu preparo para o exercício da cidadania e sua qualificação para o trabalho (BRASIL, 1996). Nesse sentido, incluir ações de educação alimentar e nutricional na formação dos alunos do ensino médio técnico tem o intuito de prover aos discentes conhecimentos que os levem a se relacionar com os alimentos, de forma saudável, a partir de práticas interdisciplinares.

Busca-se assim um diálogo entre a nutrição e a matriz curricular do curso, visando ao enriquecimento do conteúdo ensinado, já que o processo de formação deve despertar nos educandos o estímulo à adoção de novas atitudes, a busca de soluções para os problemas socioambientais existentes, bem como para o seu próprio cuidado, no intuito de adquirir melhor qualidade de vida.

Por outro lado, o trabalho com os temas transversais de forma interdisciplinar promove e estimula a discussão entre a comunidade escolar, fomentando projetos e práticas pedagógicas inovadoras. A educação alimentar e nutricional abordada através de jogos educativos, em disciplinas não tradicionalmente ligadas ao tema, amplia a visão de alunos e docentes para novas aprendizagens (SANTOS, 2012).

Nesse contexto, este relato de experiência objetiva contribuir com o desenvolvimento de ações educativas que visam à construção coletiva de conhecimento sobre alimentos e nutrição, no intuito de promover a prática independente e autônoma de hábitos alimentares saudáveis que levem à promoção e à proteção da saúde no contexto do Direito Humano à Alimentação Adequada e da garantia da Segurança Alimentar e Nutricional (BRASIL, 2012b). Munidos dessas informações, os discentes poderão atuar como multiplicadores de bons hábitos não só em suas famílias mas também na comunidade.

\section{Metodologia}

A coleta de dados foi realizada no Instituto Federal do Sertão Pernambucano Campus Floresta, localizado na Rua Projetada, S/N, no bairro do Caetano II, na cidade de Floresta, Estado de Pernambuco, no período de dezembro de 2017 a setembro de 2018, com alunos e docentes do curso técnico de agropecuária.

A população do estudo é constituída por docentes e alunos do segundo ano do curso de Ensino Médio Integrado em Agropecuária do Campus Floresta. Há, no total, duas turmas no segundo ano, uma no período matutino, composta por 28 alunos, e uma no período vespertino, composta por 17 alunos.

A seleção dos docentes (cinco selecionados) foi feita segundo o conteúdo programático analisado previamente, em que foram estudadas a ementa e a matriz curricular do curso. As disciplinas selecionadas foram: geografia, sociologia e educação física. O projeto foi apresentado aos docentes e aos alunos e, no caso dos menores de idade, aos responsáveis com um convite. Baseado no aceite, foi solicitado que 
assinassem o Termo de Consentimento Livre e Esclarecido (TCLE). No que diz respeito aos alunos, os critérios de inclusão foram: estarem matriculados regularmente no curso em todas as disciplinas elencadas, possuírem mais de $50 \%$ de assiduidade e apresentarem o Termo de Consentimento Livre e Esclarecido assinado pelo responsável e o Termo de Assentimento assinado pelo próprio aluno.

O projeto foi submetido ao Comitê de Ética em Pesquisa (CEP) da Universidade de Pernambuco (UPE), obedecendo aos preceitos da Resolução 466/12 do Conselho Nacional de Saúde (CNS), aprovado em 03 de outubro de 2017 sob o número 2.311.880. Dessa forma, a coleta dos dados realizada na instituição ocorreu entre dezembro de 2017 e setembro de 2018.

O período de coleta dos dados foi dividido em dois momentos diferentes. No ano de 2017 os docentes foram entrevistados com perguntas que abordavam seus entendimentos sobre educação alimentar e nutricional, interdisciplinaridade, temas transversais e metodologias de ensino. Em 2018, os alunos foram entrevistados antes e depois das intervenções educativas.

No intuito de aprofundar a temática, foi realizada uma revisão da literatura científica acerca do tema da educação alimentar e nutricional dentro das instituições de ensino. A pesquisa reuniu evidências relacionadas à abordagem dos temas de alimentação e nutrição nas escolas nos últimos 15 anos.

Realizou-se uma pesquisa documental, sendo que as ementas e a matriz curricular do curso de Agropecuária do instituto foram analisadas para selecionar as disciplinas e os conteúdos que oferecem pontos de contato com a educação alimentar e nutricional.

As disciplinas selecionadas foram educação física, geografia e sociologia do segundo ano do curso de Agropecuária, dos turnos manhã e tarde, já que oferecem pontos de intersecção com a temática de alimentos e nutrição. Os professores de tais matérias foram convidados a participar do projeto da EAN, que tem como principal instrumento de trabalho jogos educativos, elaborados com a colaboração dos alunos de graduação em Nutrição da Universidade de Pernambuco (UPE), selecionados através de edital.

O desenvolvimento dos jogos educativos se deu a partir do estudo das ementas, associando o assunto tratado pela disciplina às temáticas de alimentos, alimentação e nutrição. A partir disso foram elaboradas propostas sobre as quais os professores das disciplinas podiam opinar e solicitar alterações. Uma vez aprovadas pelos docentes, as propostas eram analisadas quanto à confecção com utilização de material de baixo custo e fácil acesso.

Conforme consta nos Parâmetros Curriculares Nacionais (PCN) - Saúde na educação, o professor deve exercer o papel de motivador introduzindo problemas, buscando informação e materiais de apoio, problematizando e facilitando as discussões através da formulação de estratégias para o trabalho escolar (BRASIL, 1997, p. 261). Nesse sentido, a proposta dos jogos se coloca como forma de articular os conhecimentos a serem transmitidos nas disciplinas de base comum àqueles da promoção da saúde.

Segundo Silva, Lima e Ferreira (2017), o uso de jogos lúdicos é uma proposta que contribui para dinamização do ensino ao colocar os alunos como agentes ativos na construção do próprio conhecimento, uma vez que despertam a curiosidade para o 
conhecimento científico. Utilizando-se desse artifício, as ações e intervenções educativas, em conjunto com os professores das disciplinas mencionadas, tiveram duração de dois meses, ocorrendo nos dias das aulas conforme horário da instituição, e foram implementadas levando em consideração uma abordagem crítica e interdisciplinar da educação nutricional. Por razões estruturais e situacionais da escola, o material produzido para a disciplina de geografia não pôde ser aplicado.

Para avaliação da experiência através da perspectiva dos participantes e o reconhecimento das contribuições da atividade educativa, foi utilizada a técnica dos grupos focais em que os alunos e professores puderam analisar a metodologia utilizada e os conhecimentos gerados ao longo das atividades. Os participantes foram divididos em três grupos.

Os alunos foram divididos por turno, já que as intervenções realizadas foram diferentes em cada turma. Assim, o grupo 1 foi constituído por 15 alunos do turno da manhã, o grupo 2 por 10 alunos do turno da tarde e o grupo 3 pelos professores. Essa divisão foi feita levando em consideração que, caso os docentes estivessem presentes no mesmo grupo que os alunos, isso poderia causar algum constrangimento, o que prejudicaria a fala dos discentes.

A definição de grupos focais é dada por alguns autores como uma técnica de pesquisa qualitativa que utiliza uma forma de entrevista em grupo, baseada na comunicação e na interação para coleta de informações detalhadas sobre um tópico específico, proporcionando a compreensão das atitudes, percepções e crenças do grupo sobre um produto ou serviço. Sua utilização tem se revelado útil na pesquisa avaliativa (BOMFIM, 2009).

Passada a fase da coleta de dados, chegou-se à fase de análise dos dados. A pesquisa considerou nessa fase um sentido mais amplo de análise, que abrange a interpretação, conforme coloca Minayo (2002, p. 68), por concordar que as duas estão contidas no mesmo movimento, como forma de olhar para os dados coletados.

Minayo (2002) também observa que essa etapa de análise possui três finalidades: compreender os dados coletados, confirmar ou não os pressupostos e ampliar os conhecimentos sobre o tema da pesquisa de forma articulada com o contexto cultural ao qual está inserido.

Nesse sentido, para realizar a análise dos dados qualitativos obtidos através da pesquisa, foi utilizado o método de análise de conteúdo proposto por Bardin (1977). Fezse a interpretação das respostas à luz do referencial teórico e conceitual utilizado para compor a pesquisa e do material para quantificar e definir as categorias, tomando cuidado para não distorcer aquilo que foi expresso pelos entrevistados e colocado nos grupos focais.

\section{FUNDAMENTAÇÃO TEÓRICA}

As ciências da saúde detectaram que, ao longo dos últimos quinze anos, a população brasileira tem passado por um processo de transição nutricional no qual houve o aumento do sobrepeso e da obesidade, sobretudo entre os jovens, e diminuição da subnutrição (FLORES, 2013). 
Estudos epidemiológicos apontam que esse quadro é reflexo das práticas alimentares contemporâneas do mundo globalizado, caracterizadas pelo alto consumo de alimentos industrializados e ultraprocessados, os quais apresentam estreita relação com algumas doenças crônicas associadas à alimentação, como, por exemplo, hipertensão, diabetes e dislipidemias (REINALDO et al., 2015).

A importância da alimentação e da nutrição é reconhecida pelo Estado Brasileiro e vem sendo reforçada por legislação específica, como a Lei 8.080/90, que coloca a alimentação como um "fator que condiciona e determina a saúde possibilitando o pleno desenvolvimento humano com qualidade de vida e cidadania" (BRASIL, 2012a).

Dentre as estratégias do Estado estão o Programa Nacional de Alimentação e Nutrição (PNAN) e o Programa Nacional de Alimentação Escolar (PNAE), que visam garantir aos indivíduos a capacidade de fazer escolhas saudáveis com relação à alimentação e à atividade física.

O PNAE se fundamenta na lei 11.947/09 que, em seu artigo 15, propõe que o tema alimentação e nutrição seja trabalhado através de ações educativas que perpassem o currículo escolar, de forma que a educação alimentar e nutricional seja incluída no processo de ensino e aprendizagem numa perspectiva não só de segurança alimentar e nutricional, mas também voltada para o desenvolvimento de práticas saudáveis de vida.

Por outro lado, a Lei $n^{\circ}$ 9394/96 de Diretrizes e Bases da Educação (LDB) regulamenta que o pleno desenvolvimento do educando, seu preparo para o exercício da cidadania e sua qualificação para o trabalho devem ser as prioridades do sistema educativo brasileiro (BRASIL, 1996).

Da mesma forma, os Parâmetros Curriculares Nacionais (PCN) preconizam que deve haver no currículo conteúdos de saúde que serão abordados de forma interdisciplinar e transversal integrados a todas as disciplinas, no intuito de contribuir no processo de ensino/aprendizagem para formação de crianças e adolescentes (BRASIL, 2001).

Todo esse crescente aparato jurídico culmina com a Lei $n^{\circ} 13.666$, de 16 de maio de 2018, na qual a LDB passa a incluir dentro dos temas transversais não apenas uma indicação generalizada sob o título saúde, mas a educação alimentar e nutricional como um tema da parte diversificada dos currículos da educação infantil, do ensino fundamental e do ensino médio.

Reconhece-se assim a importância de professores trabalharem com temas geradores que sejam de interesse dos alunos e estejam atrelados à sua realidade. Paulo Freire (1987) coloca que essa proposta é aplicável a qualquer disciplina, já que mobiliza diferentes conhecimentos e suas interações sem perder o referente do tema originador.

Dentro dessa proposta, verifica-se uma modificação nos currículos escolares que vêm exigindo uma nova postura dos professores e reflete a dinâmica do mundo atual. Essa transformação ocorre a reboque do constante surgimento de novas tecnologias e conhecimentos, que requerem adaptação e revisão didático-pedagógicas do processo de educação escolar (LIMA, DAMASCENO, LIMA, 2016).

Conforme ressalta Fazenda (2008), a busca da cientificidade disciplinar traz consigo o surgimento de novas motivações e de novas fronteiras existenciais, por isso as disciplinas precisam ser analisadas não apenas no lugar que ocupam na matriz curricular, mas nos saberes que contemplam, nos conceitos que enunciam e no movimento de saberes que engendram o lócus de cientificidades, as quais ganham 
status de interdisciplinares no momento em que o professor pode rever suas práticas e redescobrir novos talentos.

Nesse sentido, a interdisciplinaridade é pensada também em termos de atitude, revelando-se como uma ideia ou um projeto, cuja base caracteriza-se por uma vontade genuína de cooperação, colaboração e diálogo. Exige-se assim a disponibilidade de se partilhar o saber e o poder sem ocultá-lo, mas, ao contrário, tornando-o acessível e compreensível a outros. Busca-se a superação da fragmentação do pensamento (GATTÁS; FUREGATO, 2007).

Assim, a interdisciplinaridade aparece como alternativa do saber fragmentado, sendo difícil encontrar entre os estudiosos consenso com relação a um conceito que defina formalmente as fronteiras desse universo. Japiassu (1976), buscando um sentido epistemológico, enfatiza a intensidade das trocas e interações não só entre os especialistas, mas também entre as disciplinas.

Já para Jantsch e Bianchetti (1995 apud CARLOS, 2007), é importante destacar que o exercício da interdisciplinaridade pode ser feito individualmente, ou seja, com apenas um docente, uma vez que consiste em deslocar assistematicamente, mas de forma constante, o conhecimento disciplinar.

De qualquer forma, apesar de haver desacordo em relação à quantidade de especialistas ou disciplinas necessárias para que haja um cenário interdisciplinar, os pesquisadores consultados a respeito do assunto convergem para a ideia de que a interdisciplinaridade caminha no intuito de dialogar e integrar diferentes campos do saber em busca de entendimento e soluções para questões complexas da condição humana (MORIN, 2000).

No que se refere à EAN, para dar aos alunos instrumentos para uma prática social crítica e transformadora no tocante à alimentação e ao ambiente em que vivem, é preciso basear-se em temas como a sustentabilidade, a participação, a conscientização, a autonomia, a interdisciplinaridade, a continuidade, a coletividade e a transformação. Dessa forma, pode-se sustentar os princípios da EAN na escola, sobretudo no ensino médio (DIAS, 2013).

Vale ressaltar que o ensino médio integrado é uma modalidade em que os alunos adquirem, conjuntamente, formação propedêutica e formação profissional, assumindo formas diversas e contextualizadas com a realidade, numa perspectiva de integração entre os conhecimentos relacionados ao trabalho, à cultura, à tecnologia e à ciência (BOSCATTO; DARIDO, 2017).

Nesse cenário, de acordo com o Plano de Curso do Curso Técnico de Nível Médio Integrado em Agropecuária do Instituto Federal do Sertão Pernambucano Campus Floresta (2012), a educação profissional deverá ser articulada com o ensino regular, o que indica intercomplementaridade, mantendo a identidade dos dois.

A necessidade da formação técnica não pode ser feita de forma dissociada. Assim, as áreas agrícola e zootécnica buscam fomentar uma proposta de interdisciplinaridade entre as duas áreas de conhecimento, preparando os futuros profissionais tanto em produção vegetal quanto em produção animal (INSTITUTO FEDERAL DO SERTÃO PERNAMBUCANO, 2012). 
MERCANTE, S. C.; RUFINO, L. S. DE M.; NUNES, J. V.; LYRA, P. S.; SILVA, I. R. S. MESSIAS, C. M. B. DE. O

Além disso, espera-se que os profissionais sejam agentes de mudança no setor agropecuário, apresentando postura profissional e pessoal que alie produção e qualidade de vida. Essa expectativa ganha importância quando se observa o entorno da instituição, localizada na bacia hidrográfica do Rio Pajeú.

A agropecuária encontra-se entre as atividades econômicas do município, que possuía já em 201216.494 agricultores familiares com 7 comunidades quilombolas e 12 terras indígenas. Outro dado relevante é que o município conta com o maior rebanho de caprinos do estado de Pernambuco, mas não possui uma organização da sua cadeia produtiva, desfavorecendo o desenvolvimento das atividades rurais (INSTITUTO FEDERAL DO SERTÃO PERNAMBUCANO, 2012).

Nesse sentido, o parecer do Conselho Nacional de Educação n 16/99 corrobora a intenção de que a escola profissionalizante constitua um centro de referência naqueles campos em que atua na região onde se encontra. $E$, nesse contexto, a temática de alimentação e nutrição contribui para a formação dos alunos que poderão aumentar seus conhecimentos acerca da produção dos alimentos que poderão ser levados não só para o mundo do trabalho, como também para a vida pessoal e social.

Por outro lado, o plano de curso cita a importância do desenvolvimento de competências para a laborabilidade, a interdisciplinaridade e a contextualização na organização curricular, de forma que haja atualização permanente dos cursos e seus currículos para autonomia da escola em seu projeto pedagógico.

Assim, o curso técnico de Agropecuária apresenta a possibilidade de uma formação mais ampla através do diálogo dos componentes curriculares do núcleo comum e aqueles da área técnica como mecanismo de formação cidadã, atendendo às demandas da sociedade contemporânea, conforme colocado no seu plano de curso abaixo:

\begin{abstract}
Através da oferta do Curso Técnico de Nível Médio Integrado em Agropecuária, buscar-se-á formar profissionais habilitados para o domínio de técnicas de produção e gestão da agropecuária, na identificação dos elementos sociais e culturais da sociedade, articulando saberes locais e saberes técnico-científicos para resolução de problemas, desenvolvendo ações de auto sustentabilidade, realizando uma leitura crítica das situações da realidade em que está inserido, atuando no contexto social e profissional com respeito à diversidade. (INSTITUTO FEDERAL DO SERTÃO PERNAMBUCANO, 2012, p. 11).
\end{abstract}

\title{
RESULTADOS E DISCUSSÕES
}

Após a aplicação das atividades propostas em conjunto com os professores das disciplinas de sociologia e de educação física ao longo do período de dois meses, foi feita uma avaliação dos resultados segundo a percepção dos alunos e dos professores através dos grupos focais. Os grupos foram divididos da seguinte forma: turma da manhã com 15 alunos, turma da tarde com 10 alunos e professores, composto por apenas dois. Foram chamados para os grupos focais os três docentes que estiveram em sala de aula durante a aplicação dos jogos, mas um esteve impossibilitado de participar. 
Na turma da manhã, o ponto negativo da experiência foi a duração. Segundo os alunos, deveria ter uma frequência maior. Dois alunos sinalizaram que as aulas deveriam ser semanais durante todo o ano ou que houvesse a inclusão de mais disciplinas ao longo do ano. Sugeriram ainda que o projeto fosse aplicado às disciplinas de física, biologia e química, disciplinas com as quais veem maior relação com o tema.

Esse comentário é importante porque no começo do projeto, quando houve a apresentação às turmas a respeito das intervenções, os alunos questionaram muito sobre o que teria a ver tratar assuntos de alimentação e nutrição na disciplina de sociologia, já que não conseguiam vislumbrar nenhuma relação.

Outro comentário significativo de um aluno trata da importância da participação dos professores como colaboradores ativos no processo de ensinoaprendizagem. Para ele, foi muito mais fácil compreender os assuntos quando o professor retomava nas aulas seguintes partes dos jogos realizados.

A título de exemplo, cabe relatar a dinâmica de um dos jogos utilizados, o qual era composto por um painel feito de papel Kraft, conforme ilustra a Figura 1. Utilizando arames, foram colocados três recipientes tipo tubo de ensaio com tampa com as quantidades de sal, açúcar e gordura contidas em alguns alimentos e, ao lado, quadrados de feltro, onde os alunos deveriam colar a foto de um alimento que eles acreditavam possuir aqueles ingredientes.

Figura 1: Jogo Desmistificando os alimentos em Floresta, Pernambuco, no ano de 2018.

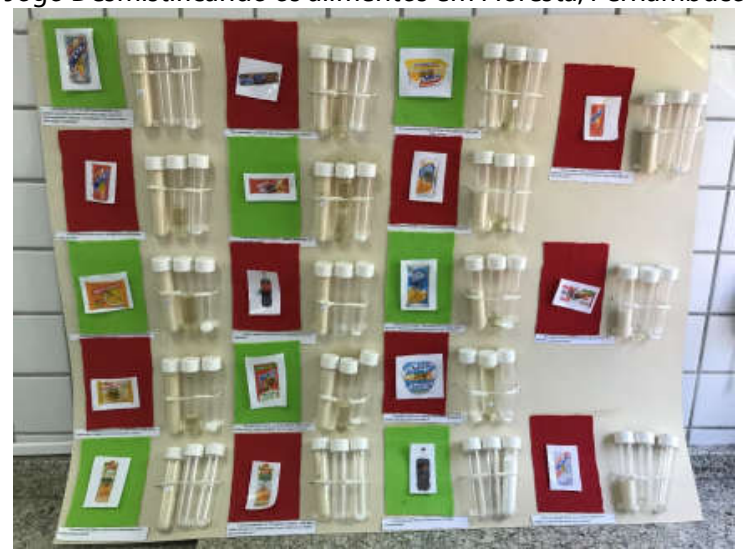

Fonte: Acervo pessoal, 2018.

Ao final do jogo, o painel é analisado em detalhes com os alunos para que eles possam ver a diferente composição dos produtos que eles costumam consumir, bem como as principais diferenças entre alimentos que a indústria chama de diet, light, integral etc.

Nesse contexto, a metodologia aplicada foi também motivo de comentário dos alunos, que viram nas intervenções algo dinâmico e diferente da rotina, ajudando no entendimento e na fixação dos conteúdos trazidos, conforme se pode constatar na fala da aluna abaixo: 
MERCANTE, S. C. RUFINO, L. S. DE M.; NUNES, J. V.; LYRA, P. S.; SILVA, I. R. S. MESSIAS, C. M. B. DE. O.

\begin{abstract}
O fato de ser dinâmico facilita o aprendizado da gente. Seria bom que isso continuasse o ano todo ou fosse feito em outras turmas para trazer mais conhecimento, já que não temos nada sobre alimentação aqui, no dia a dia. As informações foram úteis e agora procuro escolher melhor alguns alimentos, porque consigo buscar informações no rótulo (E12, 2018).
\end{abstract}

Essa mudança na relação com os alimentos, sobretudo os industrializados, também foi relatada por outros alunos, que disseram ter se interessado em buscar mais informações fora da escola em relação à produção e composição. Alguns alunos relataram que se sentiram motivados e entraram na academia, procurando um estilo de vida mais saudável.

Por outro lado, isso não apareceu no discurso do turno da tarde. Os alunos foram totalmente capazes, inclusive, de elencar alimentos que fazem mal à saúde e o porquê, lembraram-se da composição de diversos produtos, de quase tudo o que foi discutido na sala, porém assumiram que essas informações não foram capazes de fazêlos mudar de hábitos.

Alguns motivos foram elencados por eles como entraves, tais como: força de vontade, continuidade das atividades, mas, principalmente, a convivência. Vários alunos relataram que é difícil mudar um hábito, como, por exemplo, deixar de tomar refrigerante se em casa sempre tem e todos tomam.

Vale ressaltar que, assim como o turno da manhã, os alunos do turno da tarde também gostariam que as ações tivessem maior duração e fossem mais constantes, contudo não acham que deva existir uma disciplina sobre educação alimentar e nutricional com aulas semanais.

Por fim, a questão da metodologia lúdica por meio dos jogos foi motivo de elogio dos alunos, que destacaram a facilidade com que aprenderam sobre alimentos e fundamentos da disciplina de educação física, como a expressão corporal.

No que diz respeito às considerações dos professores, o resultado foi bastante positivo. Ao contrário dos alunos, os professores acharam que o tempo de aplicação foi ideal. É preciso levar em consideração, no entanto, que os professores possuem suas cargas horárias e conteúdos que precisam dar conta ao longo do ano, o que, dentro da visão deles, os deixam limitados para dedicarem mais tempo à temática.

Um dos professores colocou que alguns alunos fizeram questionamentos após as intervenções sobre por qual motivo, até então, esses assuntos referentes à alimentação não haviam sido abordados se na disciplina eles falam sobre esportes, mas nunca discutem sobre a alimentação do atleta, por exemplo.

A dinâmica e a prática foram pontos elencados pelos docentes como positivos. $\mathrm{Na}$ fala deles, os alunos estão cansados de palestras, sobretudo em educação física, porque a escola não possui quadra poliesportiva, então a disciplina apresenta muita teoria. Assim, se a abordagem não acontecesse de maneira lúdica e dinâmica, talvez não tivesse funcionado tão bem.

Um dos professores colocou que ele teve a oportunidade de relacionar muito bem os assuntos tratados nos jogos, aplicando-os em atividades avaliativas que corroboraram o aprendizado dos alunos. Nas palavras do docente: "Isso traz um ganho grande para eles e para mim, enquanto professor, porque aponta para a ideia de que 
eles conseguem articular o cotidiano deles, o que tem no prato deles, com aquilo que eles veem no quadro" $(P 5,2018)$.

Quando chegamos à discussão sobre aquilo que poderia ser melhorado ou algum ponto que os professores não tenham gostado, houve divergência sobre a natureza dos jogos. Um dos docentes considerou como prejudicial o fato de os jogos serem competitivos e não cooperativos. Segundo ele, "com os jogos cooperativos, além de se criar um sentimento de pertencimento na sala, você atenua o problema da competição entre eles e faz com que eles prestem mais atenção" $(P 5,2018)$.

P3, por outro lado, enfatiza que conseguiu ver cooperação dentro de uma competição entre eles e, por isso, gostou dos modelos utilizados e achou que foi um diferencial. Finalizando a discussão, ficou a sugestão de se criar pelo menos uma alternativa de jogos cooperativos, já que algumas turmas não possuem perfil para jogos competitivos.

Percebe-se através das colocações, tanto de alunos quanto de professores, que a metodologia aplicada com os jogos realmente alcançou as expectativas de tornar o processo mais interessante para os alunos, facilitando, assim, a aprendizagem. Além disso, fica novamente marcado o caráter processual da educação para saúde.

\section{CONSIDERAÇÕES FINAIS}

Através da pesquisa foi possível verificar que a introdução da educação alimentar e Nutricional no Campus Floresta do Instituto Federal de Educação, Ciência e Tecnologia do Sertão Pernambucano foi mais exitosa ao utilizar recursos da interdisciplinaridade. As ações educativas levadas a cabo por meio de palestras, oficinas ou ações isoladas não vinham recebendo adesão nem eram consideradas importantes por parte da comunidade acadêmica local.

Com a implantação efetiva de ações educativas conjuntas com os professores das disciplinas de sociologia e educação física, utilizando recursos lúdicos, conseguiu-se prender a atenção dos alunos envolvidos na pesquisa, despertando seu interesse para as temáticas da importância de hábitos saudáveis de alimentação e nutrição.

Isso apenas corrobora o que os autores citados colocam sobre o trabalho num cenário interdisciplinar, já que, conforme colocado por Morin (2000), por exemplo, o intuito de ter integração e diálogo entre diferentes campos do saber é que se chegue ao entendimento de questões da condição humana.

Nesse sentido, aliar a educação alimentar e nutricional às ementas das disciplinas viabilizou aos alunos o acesso a espaços de diálogo sobre segurança alimentar, indústria alimentícia, produção e qualidade dos alimentos, ampliando seus conhecimentos técnicos, necessários para a formação profissional à qual o instituto se dedica, além de permitir que os discentes tenham maior consciência para realizar escolhas alimentares saudáveis.

Esses benefícios foram expressos pelos professores envolvidos no projeto, que avaliaram a intervenção como positiva, relatando ganhos reais no desempenho dos alunos, já que, com a contextualização das disciplinas em conjunto com a EAN, a 
MERCANTE, S. C.; RUFINO, L. S. DE M.; NUNES, J. V.; LYRA, P. S.; SILVA, I. R. S. MESSIAS, C. M. B. DE. O

compreensão de atividades cotidianas como alimentação ganharam novo sentido e importância.

O mesmo entusiasmo foi sentido nos discentes que, apesar de não terem expressado mudanças efetivas nos hábitos alimentares, relataram nos grupos focais grande satisfação com as atividades por conta das informações trazidas que até então estavam ausentes no seu dia a dia escolar.

Outro ganho a ser ressaltado foi a produção de material didático na forma de jogos educativos sobre educação alimentar e nutricional, agora tema transversal obrigatório, que será disponibilizado para a comunidade acadêmica no intuito de dar continuidade ao projeto.

Fica claro, assim, que a interdisciplinaridade contribui para a implementação da educação alimentar e nutricional, podendo ser replicada em outras instituições de ensino, inclusive como um projeto a ser executado ao longo do ano letivo, já que, conforme relatado na literatura científica, ações de EAN de maior duração conseguem alcançar melhores resultados na adoção de hábitos alimentares saudáveis.

Artigo recebido em: 20/07/2020

Aprovado para publicação em: 13/10/2020

FOOD AND NUTRITION EDUCATION AT HIGH SCHOOL: ENSINO MÉDIO TÉCNICO: AN INTERDISCIPLINARY APROACH

ABSTRACT: School is a strategic environment to promote health, influencing on students eating habits. Therefore, this work objective is to contribute with the development of actions that promote independent healthy eating habits which will promote and protect health. This is an experience report associated with a qualitative approach carried out in technical high school in partnership with the sociology, physical education and geography teachers. The project made it possible to promote dialogue spaces in the school community by providing support material through educational games that brought a food and nutritional education approach in a dynamic and interactive way.

KEYWORDS: Education. Health. Educative games. Interdisciplinary.

EDUCACIÓN ALIMENTAR Y NUTRICIONAL EN SECUNDARIA TÉCNICA: UN ABORDAGE INTERDISCIPLINAR

RESUMEN: La escuela es un ambiente estratégico para la promoción de la salud, ejerciendo gran influencia en la alimentación de los alumnos. En este contexto, este relato de experiencia objetiva contribuir con el desarrollo de acciones que promuevan una práctica independiente e autónoma de hábitos alimentarios sanos llevando a la promoción y a la protección de la salud. El estudio está asociado a un abordaje cualitativo llevado a cabo en el segundo año de la enseñanza secundaria a nivel técnico con los profesores de sociología, educación física y geografía. Con el proyecto se pudo promover espacios de diálogos en la comunidad escolar entregando material de apoyo con juegos educativos los cuales trajeron la educación nutricional y alimentaria de manera dinámica e interactiva.

PALABRAS CLAVE: Educación. Salud. Juegos educativos. Interdisciplinaridad. 


\section{REFERÊNCIAS}

BARBOSA, Daise. Percepções de sujeitos de uma escola pública de ensino fundamental do Distrito Federal sobre a alimentação escolar e a educação nutricional como tema curricular transversal. 2009. $21 \mathrm{f}$. Trabalho de Conclusão de Curso (Especialização em Educação e Promoção da Saúde) - Faculdade de Enfermagem, Universidade de Brasília, Brasília, 2009.

BARDIN, L. Análise de conteúdo. Lisboa: Edições 70, 1977.

BOMFIM, Leny. Grupos focais: conceitos, procedimentos e reflexões baseadas em experiências com o uso da técnica em pesquisas de saúde. Physis: Revista de Saúde Coletiva, 2009, Rio de Janeiro, v. 19, n. 3, p. 777-796. https://doi.org/10.1590/S010373312009000300013.

BOSCATTO, J.D., DARIDO, Suraya. A educação física no Ensino Médio Integrado à Educação Profissional e Tecnológica: percepções curriculares. Pensar a Prática, 2017, Goiânia, v. 20, n. 1, p. 99-111. https://doi.org/10.5216/rpp.v20i1.39029.

BRASIL. Lei 9.394 de 20 de dezembro de 1996. Estabelece as diretrizes e bases da educação nacional. Brasília: DOU, 1996.

BRASIL. Parâmetros Curriculares Nacionais: introdução aos parâmetros curriculares nacionais. Brasília: MEC/SEF, 1997.

BRASIL. Parecer CNE/CEB no 16. Trata da Diretrizes Curriculares Nacionais para a educação profissional de nível técnico. Brasília: Câmara de Educação Básica, 1999.

BRASIL. Lei 11.947 de 16 de junho de 2009. Dispõe sobre o atendimento da alimentação escolar e do Programa Dinheiro Direto na Escola aos alunos da educação básica. Brasília: DOU, 2009. BRASIL. Política Nacional de Alimentação e Nutrição (PNAN). Brasília: Ministério da Saúde, 2012a.

BRASIL. Marco de referência de educação alimentar e nutricional para as políticas públicas. Brasília, DF: MDS; Secretaria Nacional de Segurança Alimentar e Nutricional, 2012b.

BRASIL. Lei 13.666 de 16 de maio de 2018. Altera a Lei 9.394, de 20 de dezembro de 1996, para incluir o tema transversal da educação alimentar e nutricional no currículo escolar. Brasília: DOU, 2018.

CARLOS, Jairo. Interdisciplinaridade no Ensino Médio: desafios e potencialidades. 2007. Dissertação (Mestrado em Ensino de Ciências) - Instituto de Física, Universidade de Brasília, Brasília, 2007. 
MERCANTE, S. C.; RUFINO, L. S. DE M.; NUNES, J. V.; LYRA, P. S.; SILVA, I. R. S. MESSIAS, C. M. B. DE. O

DIAS, A. de O. A gestão de Educação Alimentar e Nutricional em uma escola da Rede Pública Estadual no Município de Feira de Santana - Bahia. 2013. 161 f. Dissertação (Mestrado Profissional em Gestão e Tecnologia Aplicada à Educação) - Departamento de Ciências Humanas, Universidade do Estado da Bahia, Salvador.

FAZENDA, I. (org). Interdisciplinaridade na educação. In: FAZENDA, I. O que é interdisciplinaridade? São Paulo: Cortez, 2008. p. 18.

FREIRE, P. Pedagogia do oprimido. Rio de Janeiro: Paz e Terra, 1987.

FLORES, L.S. et. al. Tendência do baixo peso, sobrepeso e obesidade de crianças e adolescentes brasileiros. Jornal de Pediatria, 2013, v. 89, n. 5 . https://doi.org/10.1016/j.jped.2013.02.021.

GATTÁS, M.L.B., FUREGATO, Antônia Regina. A interdisciplinaridade na educação. Revista RENE, Fortaleza, 2007, v. 8, n. 1, p. 85-91.

INSTITUTO FEDERAL DE EDUCAÇÃO CIÊNCIA E TECNOLOGIA DO SERTÃO PERNAMBUCANO. Plano de Curso do Curso Técnico de Nível Médio Integrado em Agropecuária - 2012.

JAPIASSU, H. Interdisciplinaridade e patologia do saber. Rio de Janeiro: Imago, 1976.

LIMA, J. de S., DAMASCENO, M.M., LIMA, Teresa. A importância da interdisciplinaridade no Ensino no Nível Médio Técnico: a integração das disciplinas Filosofia, Literatura e Tecnologia da Confecção Industrial para a construção de um conhecimento significativo. Interagir: pensando a extensão, 2016, Rio de Janeiro, v. 22, p. 95-111. https://doi.org/10.12957/interag.2016.15914.

MINAYO, M.C. (org). Pesquisa Social: teoria, método e criatividade. Petrópolis: Vozes, 2002.

MORIN, E. Os sete saberes necessários à educação do futuro. Cortez, São Paulo, 2000.

REINALDO, E.D. F. et. al. Mudanças de hábitos alimentares em comunidades rurais do semiárido da região Nordeste do Brasil. Interciência, 2015, Santiago, v. 40, n. 5, p. 330336.

SANTOS, Lígia. O fazer educação alimentar e nutricional: algumas contribuições para reflexão. Ciência \& Saúde Coletiva, 2012, Rio de Janeiro, v. 17, n. 2, p. 453-462. http://doi.org/10.590/S1413- 81232012000200018.

SILVA, E.K.S., LIMA, J.P.F., FERREIRA, Maricélia. "Descobrindo os elementos químicos": jogo lúdico proporcionando uma aprendizagem significativa sobre a tabela periódica. Revista de Pesquisa Interdisciplinar, 2017, Cajazeiras, v. 1, Edição Especial, p. 228-237. https://dx.doi.org/10.24219/rpi.v1iEsp.87 
Soraia Correa Mercante: Possui graduação em Letras - Português pela Universidade de Pernambuco (2018), graduação em Nutrição pela Universidade Federal do Estado do Rio de Janeiro(2007), graduação em Letras - Espanhol pela Universidade Estácio de Sá(2019) e mestrado-profissionalizante em Formação De Professores E Práticas Interdisciplinares pela Universidade de Pernambuco(2018). Atualmente é Técnica Administrativa Nível E do Instituto Federal do Sertão Pernambucano.

Orcid: https://orcid.org/0000-0001-7492-0705

E-mail: scmercante@hotmail.com

LuCIRLÂNDIA Shella De Morais RufinO: Graduanda do curso de Nutrição pela Universidade de Pernambuco - UPE. Petrolina, PE.

Orcid: https://orcid.org/0000-0002-0911-5635

E-mail: lucirlandiasheila@smail.com

Juliana VieIRA Nunes: Graduanda do curso de Nutrição pela Universidade de Pernambuco - UPE. Petrolina, PE.

Orcid: https://orcid.org/0000-0002-6072-1921

E-mail: jujuvieira987@gmail.com

Poliana Simões LyRA: Graduanda do curso de Nutrição pela Universidade de Pernambuco - UPE. Petrolina, PE.

Orcid: https://orcid.org/0000-0002-6084-1261

E-mail:polianalyra@hotmail.com

INGRID Raphaela Souza SIlva: Graduanda do curso de Nutrição pela Universidade de Pernambuco - UPE. Petrolina, PE.

Orcid: https://orcid.org/0000-0003-2987-0758

E-mail: ingridraphaela96@gmail.com

Cristhiane Maria Bazílıo de OMena messias: Possui graduação em Nutrição pela Universidade Federal de Alagoas (2006) e Doutorado em Ciências pela Universidade Federal de Alagoas (2012). Atualmente é Professora Livre Docente, Associada II G da Universidade de Pernambuco - Campus Petrolina, do curso de graduação em Nutrição; Docente Permanente do Programa de Pós-Graduação Stricto Sensu Formação de Professores e Práticas Interdisciplinares (PPGFPPI) - Nível mestrado profissional.

Orcid: https://orcid.org/0000-0002-1991-0376

E-mail: cristhiane.omena@upe.br

Este periódico utiliza a licença Creative Commons Attribution 3.0, para periódicos de acesso aberto (Open Archives Iniciative - OAI) 